\title{
158
}

IX - The Decomposition of Alcohol and its Homologues by the joint action of Aluminium and its Halogen Compounds.

By J. H. Gladstone, Ph.D., F.R.S., Fullerian Professor of Chemistry in the Royal Institution, and ALFRED TRIBE, F.C.S., Lecturer on Chemistry in Dulwich College.

IN our paper on the joint action of aluminium and the aluminiumhalogens on water, the fact, among others, was established that water is decomposed by these agents, the hydrogen obtained being equivalent to the metal employed.

The exact products resulting from the decomposition of water may be known a priori; but with regard to any complex organic body it is very different. Alcohol, for example, if it should be decomposed when subjected to the action of aluminium and its iodide, might be expected to yield either ethyl hydride and aluminic oxide, or hydrogen and aluminic ethylate. If the former, the reaction would give an easy means of obtaining the hydrides of the alcohol-radicals; if the latter, it would add another member to an important class of organo-metallic bodies, and possibly supply the means of hydrogenising many organic substances soluble in alcohol, without the destructive action of acids or alkalis. These considerations induced us to undertake the study of the action of aluminium jointly with its halogens on alcohol and its homologues.

Alcohol was found to have no effect on aluminium alone, even when boiled with it for some hours.

2 grams of iodine were dissolved in 20 c.c. of absolute alcohol, and placed in a flask containing 2 grams of finely-cut aluminium foil. Action commenced immediately, the temperature inside the flask rising so rapidly as to necessitate agitation in cold water. In the course of three minutes the colour of the iodine had entirely disappeared.

\begin{tabular}{|c|c|c|c|}
\hline In 2 minutes. . & \multicolumn{3}{|c|}{350 c.c. gas were collected. } \\
\hline Next 1 minute ...... & 650 &, & , \\
\hline, 44 minutes. ..... & 1000 &, & , \\
\hline$\therefore \ldots$ & 100 & ", & $"$ \\
\hline
\end{tabular}

The residue in the flask being now quite solid, 20 c.c. more alcohol were added, when gas was again evolved. In 17 minutes from the commencement the action ceased, 2184 c.c. of gas having been obtained.

In another experiment, the same quantity of materials was em- 
ployed as in the previous trial, the flask with its contents being from the beginning immersed in water at $17^{\circ} \mathrm{C}$. In two minutes evolution of gas commenced, and the free iodine disappeared in 39 minutes.

$$
\begin{aligned}
& \text { Gas collected during first hour .... } 310 \text { c.c. }
\end{aligned}
$$

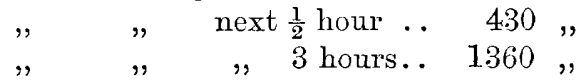

Evolution continued slowly for 15 hours longer, the total gas collected measuring 2165 c.c.

The gas obtained gave complete contraction on explosion with oxygen, and burnt with a non-luminous flame, the only product of combustion being water, showing that the gaseous product of the action is hydrogen.

The quantity of hydrogen equivalent to 2 grams of aluminium, minus the quantity necessary to combine with 2 grams of iodine, is 2277 c.c. It is evident, therefore, that hydrogen is obtained equivalent to the metal used up not in combination with iodine.

Our object in employing free iodine in the experiments just described was simply because it offered the most direct and ready means of preparing a known quantity of aluminium iodide. We, however, thought it of importance to make the following experiment, with the view of ascertaining whether free iodine was necessary to start the reaction.

$2 \cdot 2$ grams of aluminic iodide (equivalent to 2 grams of iodine) were dissolved in 40 c.c. absolute alcohol, and added to 2 grams of cut aluminium foil, the temperature being $17^{\circ} \mathrm{C}$. Evolution of gas commenced in 35 minutes.

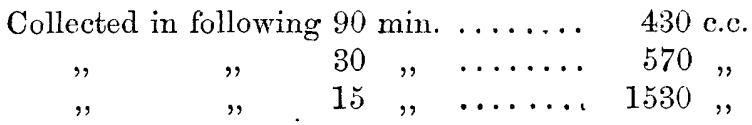

when action practically ceased. The temperature rose considerably during the reaction. The total gas collected, after allowing for temperature, \&c., measured 2381 c.c., the quantity theoretically obtainable from the aluminium employed being 2452 c.c.

It is evident from the results of this experiment that alcohol suffers decomposition by the joint action of aluminium and its iodide; and on comparing it with Experiment I, it is noticeable that the reaction is considerably increased in rapidity by the iodine being free, which is doubtless to be attributed to the greater disturbing influence exercised on the alcohol by the element when free than when in combination.

The residue left in the flask was pasty and greyish white in colour; and as hydrogen is the only gaseous product of the reaction, it is 
hard to conceive of it consisting of other than aluminic ethylate, $\mathrm{Al}_{2}\left(\mathrm{C}_{2} \mathrm{H}_{5} \mathrm{O}\right)_{6}$, mixed with about one-thirteenth of an equivalent of aluminic iodide, or of one-sixth of an equivalent of aluminic iodo-ethylate, $\mathrm{Al}_{2}\left\{\begin{array}{l}\left.\mathrm{C}_{2} \mathrm{H}_{5} \mathrm{O}\right)_{3} \\ \mathrm{I}_{3} .\end{array}\right.$

Heated to $100^{\circ} \mathrm{C}$. it dried up, so that it could be easily powdered, a quantity of alcohol having distilled. On further heating in a paraffin bath to $275^{\circ} \mathrm{C}$. it became fluid at about $180^{\circ}$, alcohol mixed with an oily body containing iodine, and having the odour of ethyl iodide, passing over during the whole time. After keeping the fused residue at $275^{\circ} \mathrm{C}$. until nothing more distilled, 2.407 grams were removed, and the alumininm and iodine were determined. 4388 aluminium and 03152 iodine were obtained. Now, since iodine and aluminium were originally together in equal quantities, it is evident that the $2 \cdot 407$ grams of residue must have lost $\cdot 4072$ of iodine; and as this appeared in combination with ethyl, there can be little doubt that it resulted from the decomposition of aluminic iodo-ethylate, thus :-

$$
\mathrm{Al}_{2}\left\{\begin{array}{l}
\left(\mathrm{C}_{2} \mathrm{H}_{5} \mathrm{O}\right)_{3} \\
\mathrm{I}_{3}
\end{array}=\mathrm{Al}_{2} \mathrm{O}_{3}+3\left\{\begin{array}{l}
\mathrm{C}_{2} \mathrm{H}_{5} \\
\mathrm{I}
\end{array}\right.\right.
$$

which would of course add to the residue a quantity of aluminic oxide equivalent to the iodo-etbylate decomposed. Calculating the composition of the $2 \cdot 407$ grams of residue from its analysis on this hypothesis, we have :-

Aluminic ethylate equivalent to the aluminium found, minus the metal in the under-mentioned $\mathrm{Al}_{2} \mathrm{O}_{3}$ and $\mathrm{Al}_{2}\left\{\begin{array}{llllll}\left(\mathrm{C}_{2} \mathrm{H}_{5} \mathrm{O}\right)_{3} & \ldots & \ldots & \ldots & \ldots & 2 \cdot 2273 \\ \mathrm{I}_{3} & & & \end{array}\right.$

$\begin{array}{lllll}\text { Iodo-ethylate equiv. to iodine found .. } & \text {. } & \text {. . } & 0.0472\end{array}$

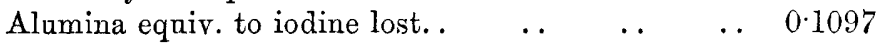

$2 \cdot 3842$

The close agreement of these numbers leaves little doubt as to the composition of the solid products of the reaction, and we have other grounds for believing in the existence of the aluminic iodo-ethylate and its decomposition according to the above formulæ. These grounds we hope to set forth in a future communication.

\section{Aluminic Ethylate.}

The residue, heated above $275^{\circ}$ by means of a gas flame, boiled, and at the same time underwent a partial decomposition; a small amount of a yellowish-white substance containing aluminium condensed in the tube of the condenser; a little liquid containing alcohol and some 
aluminium compound decomposible by water was found in the receiver; some quantity of gas was collected which contained 86.4 p. c. of an olefine; while in the flask after the action, was found alumina and a mere trace of iodide. The following equation represents the probable action of heat on such a body as aluminic ethylate:-

$$
\mathrm{Al}_{2}\left(\mathrm{C}_{2} \mathrm{H}_{5} \mathrm{O}\right)_{6}=\mathrm{Al}_{2} \mathrm{O}_{3}+3 \mathrm{C}_{2} \mathrm{H}_{5} \mathrm{HO}+3 \mathrm{C}_{2} \mathrm{H}_{4},
$$

which is in accordance with what we obtain by the action of heat on our solid residue.

The foregoing results led us to hope that the ethylate might be obtained in the pure state by distillation under diminished pressure. The residue from the usual quantities of 2 grams of aluminium, 2 grams iodine, and 40 c.c. alcohol, after heating for some time at about $270^{\circ} \mathrm{C}$., was gently heated over a gas lamp, a pump connected with the condenser tube being kept at work. A quantity of vapour passed over which immediately condensed in the tube to a yellowish-white solid. The alumina left in the flask weiglred only 0.372 gram, which shows that 90 p. c. of the metal taken passed over in combination. The solid body thas distilled was found to be quite free from iodine. It dissolved slightly in absolute alcohol, from which solution water precipitated aluminic hydrate. Hot water decomposes it very rapidly, alcohol and aluminic hydrate being the products of decomposition. It melts at $115^{\circ} \mathrm{C}$, and boils somewhere about the limits of the mercurial thermometer. Exposed to the ordinary air it quickly decomposes, alumina and doubtless alcohol being produced.

1.062 gram dissolved in dilute nitric acid and precipitated by ammonia gave $0.330 \mathrm{Al}_{2} \mathrm{O}_{3}$; the calculated quantity for aluminic ethylate being 0.336 .

In this aluminic ethylate, the existence of which we may now consider well established, we have the second instance of an organometallic body containing oxygen capable of distillation, cacodylic oxide having been the first recorded.

It now appeared of interest to ascertain whether in this reaction ethyl alcohol could be replaced by other alcohols of the same series, and whether the iodide could be replaced by its chlorine or bromine analgone.

Aluminium and aluminic iodide boiled with methyl alcohol for two hours gave no result, but on replacing the methylic by amylic alcohol, action took place, the course of which is shown by the following experiment:-

$2 \cdot 14$ grams of aluminic iodide were dissolved in 40 c.c. of amyl alcohol, and the mixture added to 2 grams of finely cut aluminium 
foil. No gas was evolved, or any signs of action in 15 minutes at the ordinary temperature; at $100^{\circ} \mathrm{C}$. evolution of gas commenced in 8 minutes, and the action became so rapid as to necessitate the agitation of the flask in cold water. In 10 minutes 1,500 c.c. of gas wcre collected, and in 25 minutes more the action ceased, the total hydrogen obtained measuring 2,272 c.c., a quantity practically identical with what was obtained in the experiments with ethyl alcohol.

Alcohol boiled with aluminic chloride and the metal for two hours underwent no decomposition. The bromide, however, was found to bring about its decomposition, but less energetically than tbe iodide, as the following experiment illustrates :-

1.44 gram of aluminic bromide (equivalent to the iodide employed previously) was dissolved in 40 c.c. absolute alcohol, and added to the usual amount of cut aluminium foil. In 12 minutes evolution of gas commenced, and in the next 60 minutes 160 c.c. had collected; in the next 38 minutes 840 c.c. more, and this continued in a diminishing ratio for five hours, the total hydrogen obtained measnring 2,275 c.c., which is again nearly equivalent to the quantity of aluminic ethylate which it is theoretically possible to obtain.

The reaction just described appears to us to be remarkable in more respects than one. We have here a powerful agent for separating oxygen and oxy-radicals from their compounds; and we have the peculiar fact revealed that a body so stable as alcohol is easily split up by the conjoint action of two substances, neither of which singly and under the same conditions has the least action upon it. 